\title{
VACUUM-PACKAGED MICRO FUEL REFORMER FOR HIGH THERMAL EFFICIENCY AND LOW PACKAGE TEMPERATURE
}

\author{
A. Kasuga, S. Tanaka and M. Esashi \\ Tohoku University, Sendai, Japan
}

\begin{abstract}
A fully-microfabricated wafer-level vacuum package of a micro fuel reformer was designed, fabricated and tested. For thermal insulation, a high-temperature reactor is suspended by microfabricated tubes, in which fuel and reformed gas flow, and is vacuum-packaged by anodic bonding. Conductive heat loss through air in the package was investigated by making the packaging pressure as a parameter. The measured heat loss is $1.2 \mathrm{~W}$ at a reforming temperature of $240{ }^{\circ} \mathrm{C}$, showing a potential to realize a micro fuel reformer with a thermal efficiency of $75 \%$. Also, the temperature of the package outside is as low as $60{ }^{\circ} \mathrm{C}$, which is enough to install the micro fuel reformer in portable electronics.
\end{abstract}

\section{INTRODUCTION}

Recently, increasing demand for the longer operation time of portable devices has made fuel cells attractive as portable energy sources. Among several types of fuel cell, direct methanol fuel cell (DMFC) is the most widely being developed, because liquid methanol, which is easy to store and handle, is convenient for uses. However, it still suffers from low power density in comparison with hydrogenfueled polymer electrolyte membrane fuel cell (PEMFC). If a practical compact and high efficiency hydrogen source is available, the hydrogen-fueled PEMFC will become more advantageous in power density than the DMFC.

There are several methods to supply hydrogen to fuel cells, e.g. using compressed hydrogen, liquid hydrogen, fuel reforming and chemical hydride. For portable devices, the best method to supply hydrogen seems using a micro fuel reformer fabricated by micro electro mechanical system (MEMS) technology. MEMS technology is useful to fabricate and integrate a reforming reactor, a carbon monoxide remover, a catalytic combustor etc. in a small volume [1-3]. Furthermore, excellent thermal isolation of reaction areas is possible using thin film microstructures fabricated by MEMS technology [4-7].

In the previous study, we have demonstrated a high power density of $5.9 \mathrm{~W}$ LHV/2.8 cc with a fullymicrofabricated fuel reformer [8]. However, the previous device had no thermal insulation structure, and its thermal efficiency was as low as $36 \%$. In this paper, we propose a vacuum-packaged micro fuel reformer for high thermal efficiency and low package temperature.

\section{CONCEPT}

Varieties of hydrocarbons such as methanol, propane, butane and gasoline can be used as hydrogen sources by reforming. For portable applications, methanol is generally selected, because methanol reforming proceeds at a relatively low temperature around $250{ }^{\circ} \mathrm{C}$, and is easier than that of other hydrocarbons, In addition, methanol will become a standard fuel after direct methanol fuel cells
(DMFCs) are commercialized for portable applications. To produce hydrogen from methanol, steam reforming is generally used. The total reaction of methanol steam reforming is given by

$\mathrm{CH}_{3} \mathrm{OH}+\mathrm{H}_{2} \mathrm{O}+49.45 \mathrm{~kJ} / \mathrm{mol} \rightarrow 3 \mathrm{H}_{2}+\mathrm{CO}_{2}$.

The total reaction is endothermic. Thus, supplying heat to a reactor makes the reaction go forward to produce hydrogen.

Figure 1 shows a system diagram of a methanol reformer. The evaporator and the reformer are heated by the heater, which is practically a catalytic combustor. To reduce the heat loss from these high temperature parts to low temperature parts of the reformer, a vacuum packaging is used. The chip-level vacuum packaging of a micro fuel reformer was presented by Casio Computer in 2006 [9]. However, a wafer-level vacuum package was not reported to the best of our knowledge. In this study, we developed the wafer-level vacuum packaging technology for a fullymicromachined fuel reformer.

\section{STRUCTURE}

Figures 2 and 3 show the exploded and cross-sectional structure of our vacuum-packaged micro fuel reformer, respectively. Silicon and Pyrex glass layers are anodically bonded, constituting the micro fuel reformer. The second layer made of a $1 \mathrm{~mm}$ thick Pyrex glass substrate has a suspended reactor with a volume of $0.035 \mathrm{cc}$ formed by sandblast. The third layer is a $60 \mu \mathrm{m}$ thick silicon layer, which has a heater and temperature sensor made of $\mathrm{Pt} / \mathrm{Ta}$. The resistance of the heater/temperature sensor is $480 \Omega$ at room temperature. The glass beams with a microchannel suspending the reforming chamber scarcely contribute for heat conduction from the reaction area to the surrounding package due to low thermal conductivity of glass. The thin silicon with high thermal conductivity prevents hot spots in the microchannels and the reactor.

The first and forth layers package the second and third layers in vacuum. The first layer has a fuel inlet, a product outlet and a diaphragm, which is used to monitor vacuum level inside the cavity. The vacuum packaging is completed by sputtering metal into the electrical contact holes on the forth layer in vacuum.

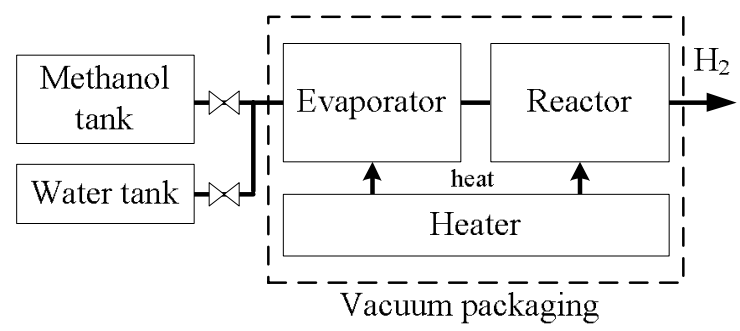

Figure 1: Diagram of a vacuum-packaged methanol reforming system. 


\section{CALCULATION}

Heat losses to the package and the temperature of the reactor are theoretically calculated. Heat losses by conduction, radiation and convection are considered to estimate the thermal efficiency of the system. Figure 4 shows possible heat flows in the micro fuel reformer. The equations used in this calculation are provided below.

\section{Conductive heat loss}

The meandered suspending tubes are approximated as straight beams with conductive heat loss expressed by the one-dimensional heat flow equation:

$Q_{\text {conduc }}=\lambda \cdot A \cdot \frac{T_{\text {reactor }}-T_{\text {package }}}{L} \cdot 2$,

where $\lambda$ is a heat conduction coefficient, $A$ is the sectional area of the beams, $L$ is the length of the beams, $T_{\text {reactor }}$ is the temperature of the reactor, $T_{\text {package }}$ is the temperature of the package. Heat is lost from two beams, and thus the heat loss is doubled in Eq. (2).

\section{Radiative heat loss}

Assuming that the device is a black-body source, the radiative heat loss is given by the Stefan-Boltzmann's equation:

$$
Q_{\text {rad }}=\sigma S\left(T_{\text {reactor }}^{4}-T_{\text {package }}^{4}\right),
$$

where $\sigma$ is a Stefan-Boltzmann coefficient, and $S$ is a surface area.

\section{Heat loss by product gas}

Product gas conveys heat from the reactor to the surrounding environment, resulting in heat loss. It is assumed that the product gas is composed of $75 \%$ hydrogen and $25 \%$ carbon dioxide, and that the flow rate is $30 \mathrm{sccm}$. The heat loss by the products gas is expressed as

$$
Q_{\text {pro }}=\left(C_{\mathrm{H}_{2}} \rho_{\mathrm{H}_{2}} F_{\mathrm{H}_{2}}+C_{\mathrm{CO}_{2}} \rho_{\mathrm{CO}_{2}} F_{\mathrm{CO}_{2}}\right) \cdot\left(T_{\text {package }}-T_{0}\right) \text {, }
$$

where $C$ is a specific heat at a constant volume, $\rho$ is the density of products gas, $F$ is a mass flow rate, $T_{0}$ is the temperature of environment.

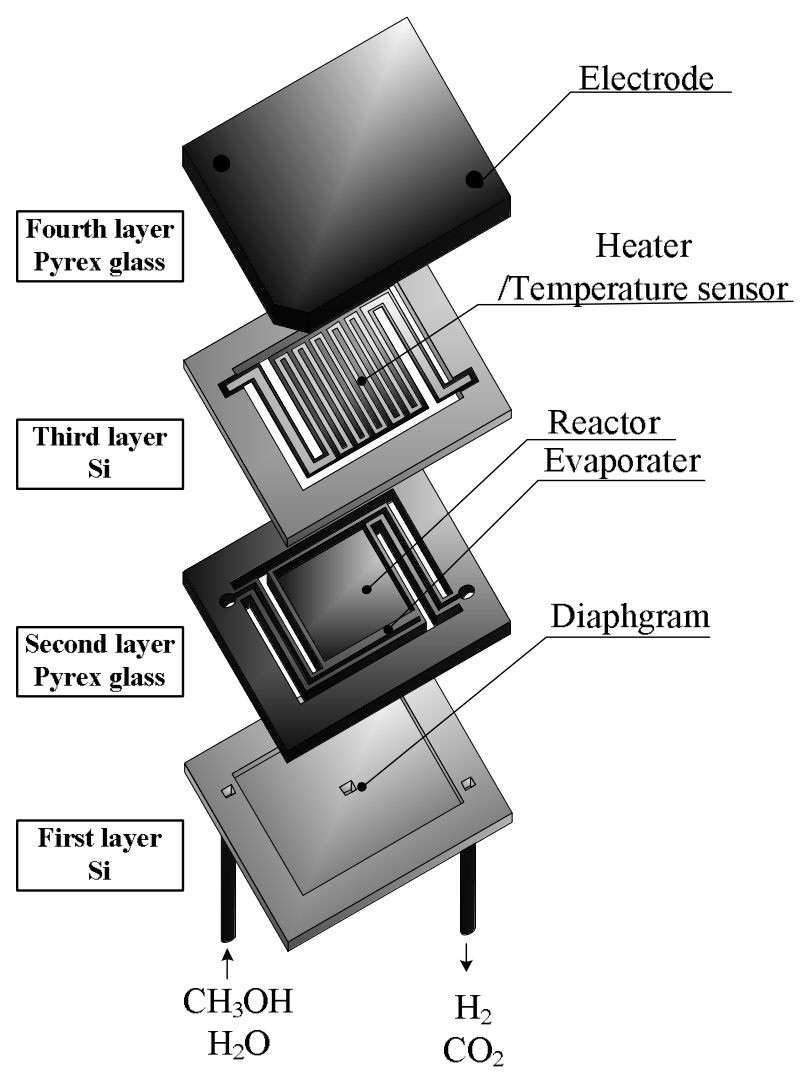

Figure 2: Exploded structure of the vacuum-packaged micro fuel reformer.

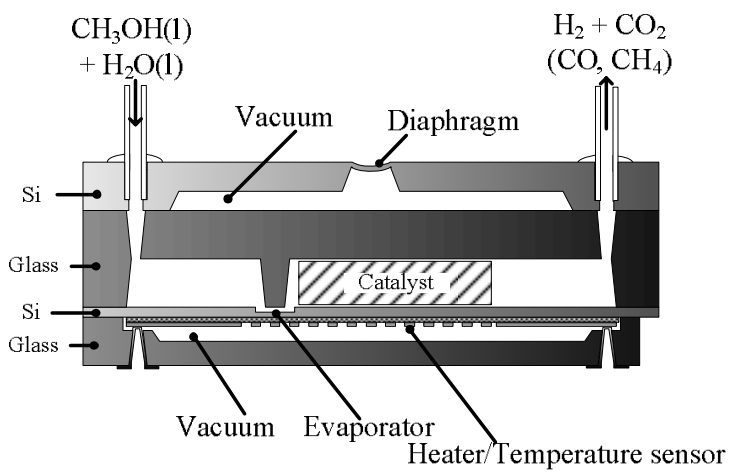

Figure 3: Schematic cross section of the vacuum-packaged micro fuel reformer.

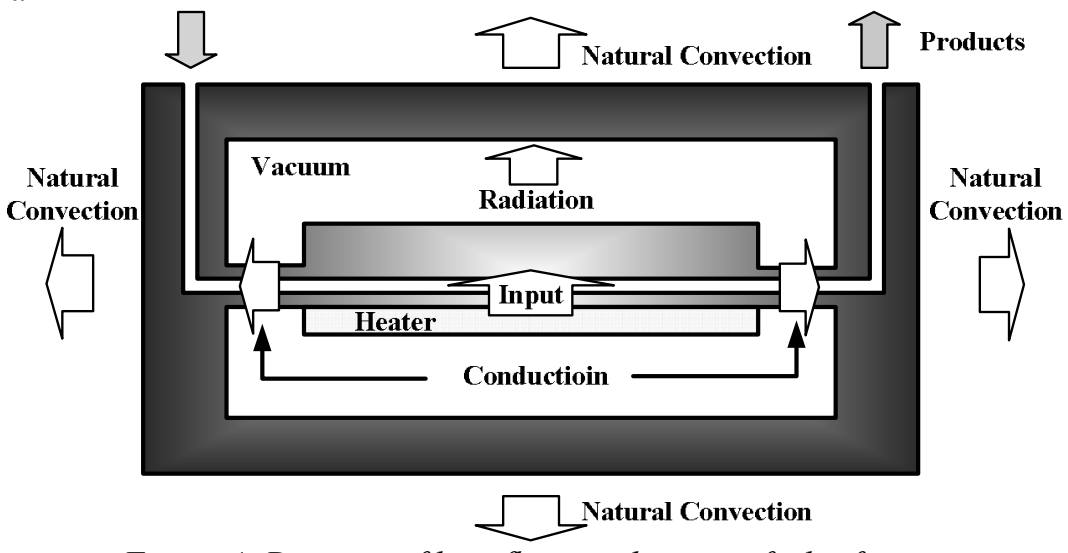

Figure 4: Diagram of heat flows in the micro fuel reformer. 


\section{Natural convective heat loss}

The equations of natural convective heat transfer on the top, bottom and side surface are different. The convective heat loss at the top surface is given as

$$
Q_{\text {convec }}^{\text {top }}=A \cdot \frac{\lambda}{L}\left(T_{\text {package }}-T_{0}\right)(G r \cdot \operatorname{Pr})^{1 / 4} \text {. }
$$

The convective heat loss at the bottom surface is given as

$Q_{\text {convec }}^{\text {bottom }}=0.14 \cdot A \cdot \frac{\lambda}{L}\left(T_{\text {package }}-T_{0}\right)(G r \cdot \operatorname{Pr})^{1 / 3}$.

The convective heat loss at the side surface is given as

$$
\begin{aligned}
Q_{\text {convec }}^{\text {side }}=0.51 \cdot A \cdot \frac{\lambda}{L}\left(T_{\text {package }}\right. & \left.-T_{0}\right)^{1 / 3} \\
& \cdot \frac{\operatorname{Pr}^{1 / 2}}{(0.95+\operatorname{Pr})^{1 / 4}} G r^{1 / 3},
\end{aligned}
$$

where $A$ is a surface area, $\lambda$ is a heat conduction coefficient of air, $L$ is a characteristic length, $P r$ is Prandtl number, and $\mathrm{Gr}$ is Grashof number.

Figure 6 shows calculated heat losses as functions of the temperature of the reactor. At low temperature, the radiative heat loss and the conductive heat loss through the silicon beams occupy most of the total heat loss. At high temperature, including a reforming temperature of $250{ }^{\circ} \mathrm{C}$, the radiative heat loss grows up to the largest one. The total heat loss is $1.2 \mathrm{~W}$ at the reforming temperature.

If this micro fuel reformer achieves a power density identical to that in the previous work [8], a hydrogen production at 3.6 W LHV is expected, and thus the thermal efficiency becomes $75 \%$. Further reduction of the radiative heat loss, which is the largest heat loss, is possible by the deposition of a low emissivity material on the hot or cold wall in the micro fuel reformer.

\section{EXPERIMENTAL}

\section{Measurement setup}

Figure 7 shows a measurement setup to investigate the thermal insulation performance of the vacuum package. The fabricated device with the diaphragm mechanically penetrated was connected to vacuum pumps, and the inside of the package was pumped out. The reactor inside the vacuum package was heated by applying a constant current to the heater fabricated on the third silicon layer. The temperature of the reactor and the package outside was measured with the embedded temperature sensor and a thermocouple, respectively.

\section{Effect of packaging pressure}

Conductive heat loss through air remaining in the package at various pressures was experimentally measured. Figure 8 shows the conductive heat loss as a function of the chamber pressure at an applied current of $30 \mathrm{~mA}$. As found in the figure, the effect of the pressure on the reduction of the convective heat loss is large from $10^{3} \mathrm{~Pa}$ to $1 \mathrm{~Pa}$. The kinetic theory of gases predicts that the thermal conductivity of a gas is a function of the pressure, when the mean free

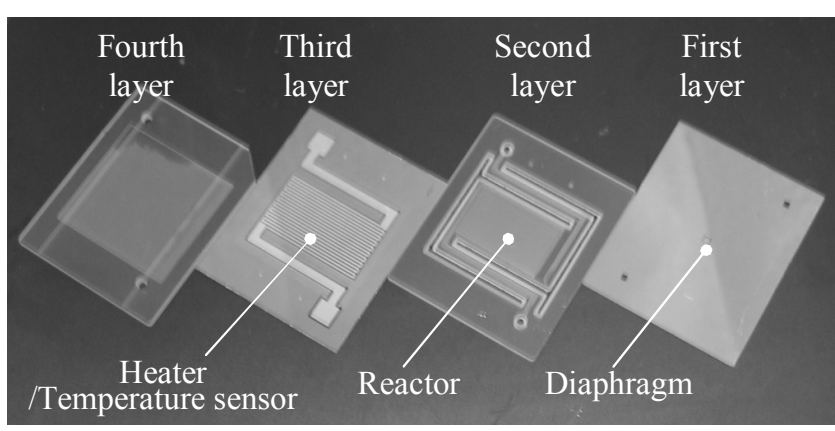

Figure 5: Photograph of the fabricated layers.

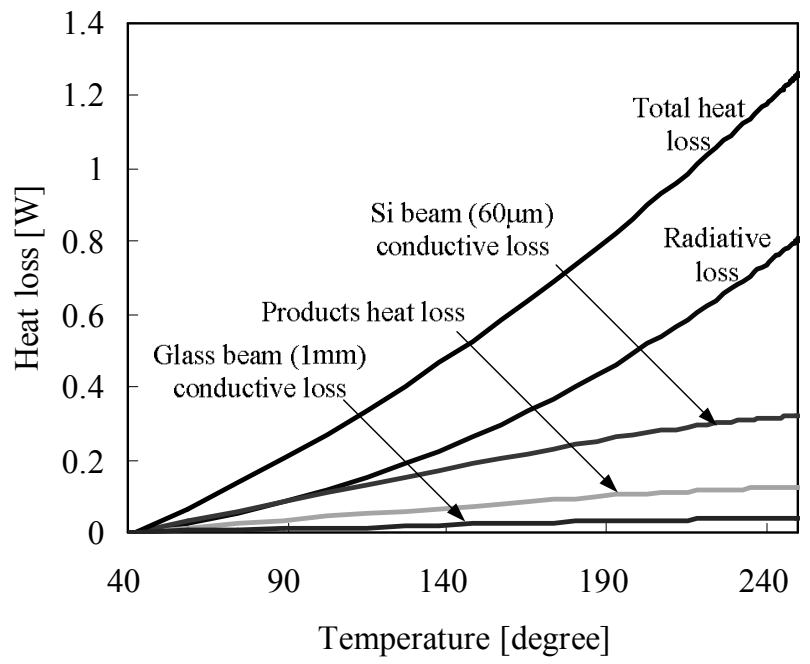

Figure 6: Calculated heat losses from the reactor to the package as a function of the temperature of the reactor.

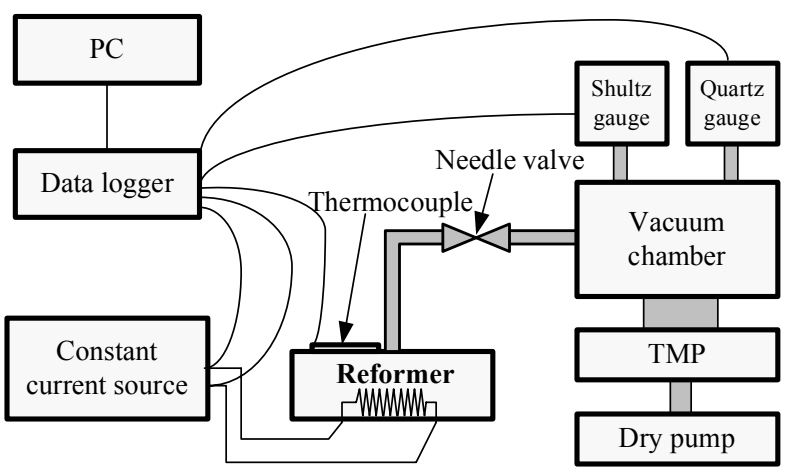

Figure 7: Schematic diagram of the measurement setup to measure thermal insulation performance.

path of gas molecules is limited by the size of enclosure. The energy flux of gas conduction is given by

$Q_{\text {conduction }}^{\text {gas }}=\frac{1}{3} \bar{c} \lambda C_{V, m}[\mathrm{~A}] \frac{d T}{d x}$

where $\bar{c}$ is an average gas molecule velocity, $\lambda$ is a mean free path, $C_{\mathrm{V}, \mathrm{m}}$ is a volume constant molar heat capacity, [A] is the molar concentration of gas $\mathrm{A}, T$ is a gas temperature, and $x$ is the length in a diffusion direction. When $\lambda$ is limited by the size of enclosure, $\lambda$ is considered as a constant value, whereas the molar concentration of the gas is proportional to the pressure. Therefore, the conductive 


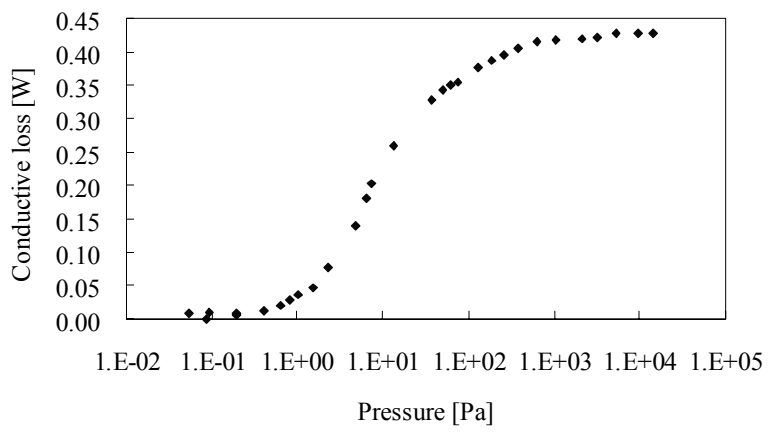

Figure 8: Conductive heat loss through air in the package as a function of the pressure. Heating current is constant at $30 \mathrm{~mA}$.

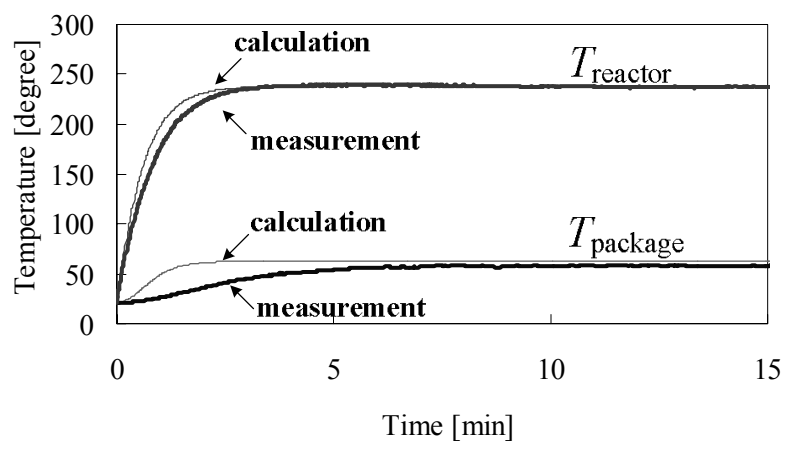

Figure 9: Measured and calculated temperatures of the reactor $\left(T_{\text {reactor }}\right)$ and the package $\left(T_{\text {package }}\right)$ at a heating power of $1.2 \mathrm{~W}$. In the steady state, $T_{\text {reactor }}$ and $T_{\text {package }}$ are $240{ }^{\circ} \mathrm{C}$ and $60^{\circ} \mathrm{C}$, respectively.

heat loss is proportional to the pressure below $10^{3} \mathrm{~Pa}$. At higher pressure above $10^{3} \mathrm{~Pa}$, the pressure has little influence on the conductive heat loss, because decrease in the molar concentration of the gas and increase in the mean free path cancel each other.

This experiment found that the gas conductive heat loss becomes below $0.1 \mathrm{~W}$, if the packaging pressure is below 1 $\mathrm{Pa}$. By packaging below this pressure, the conductive heat loss is practically negligible in comparison with solid conductive and radiative losses.

\section{Comparison of experiment and calculation}

The reactor started to be heated using the inner heater at a constant power of $1.2 \mathrm{~W}$, and the temperatures of the reactor and the package were measured. The packaging pressure was $7 \times 10^{-3} \mathrm{~Pa}$. Figure 9 shows an experimental result with a calculation result. The calculation took account of heat losses by conduction, radiation, convection and gas flow. The result shows the calculation well agrees with the experiment. When a power of $1.2 \mathrm{~W}$ was applied to the heater, the reactor reached a reforming temperature of 240 ${ }^{\circ} \mathrm{C}$ in $3 \mathrm{~min}$, while the temperature of the package outside was as low as $60^{\circ} \mathrm{C}$.

This result demonstrates that the heat loss is only $1.2 \mathrm{~W}$ during fuel reforming at $240{ }^{\circ} \mathrm{C}$. If this device achieves a power density identical to the previous work [8], a hydrogen production at $3.6 \mathrm{~W}$ LHV is expected, and thus the thermal efficiency becomes as high as $75 \%$.

\section{CONCLUSION}

Vacuum packaging technology for thermal insulation of a micro fuel reformer was developed. A high-temperature reactor is suspended by microfabricated tubes, in which fuel and reformed gas flow, and is vacuum-packaged by anodic bonding. The fabrication and vacuum packaging of the micro fuel reformer are fully based on MEMS technology, and thus wafer-level.

Thermal insulation performance was evaluated by making packaging pressure as a parameter. Conductive heat loss through air in the package decreases from a packaging pressure of $10^{3} \mathrm{~Pa}$ to $1 \mathrm{~Pa}$. At a packaging pressure below 1 $\mathrm{Pa}$, the total heat loss including heat losses by conduction, radiation, convection and gas flow was as low as $1.2 \mathrm{~W}$, when the reactor reached a reforming temperature of $240^{\circ} \mathrm{C}$. This suggests a potential to realize a micro fuel reformer with a thermal efficiency of $75 \%$. At that time, the temperature of the package outside was as low as $60{ }^{\circ} \mathrm{C}$, which is low enough to install the micro fuel reformer in portable electronics.

\section{AKNOWLEDGEMENT}

This work was supported through the Creative Scientific Research Program (No. 18GS0203) by the Ministry of Education, Science, Culture and Sports (MEXT).

\section{REFERENCES}

[1] Chang K S, Tanaka S and Esashi M 2003 MEMS-based fuel reformer with suspended membrane structure IEEJ Trans.SM 123 346-50

[2] Pattekar A V and Kothare M V 2004 A microreactor for hydrogen production in micro fuel cell applications $J$. Microelectromech. Syst. 13 7-18

[3] Terazaki T, Nomura M, Takeyama K, Nakamura O and Yamamoto T 2005 Development of multi-layered microreactor with methanol reformer for small PEMFC J. Power Sources 145 691-6

[4] Srinivasa R, Hsing I M, Berger P E, Jensen K F, Firebaugh S L, Schmidt M A, Harold M P, Lerou J J and Ryley J F 1997 Micromachined reactors for catalystic partial oxidation reactions AIChE J. 43 305969

[5] Zhang C, Najafi K, Bernal L P and Washabaugh P D 2001 An integrated combustor-thermoelectric micro power generator Proc. Transducers '01 34-7

[6] Schaevitz S B, Franz A J, Jensen K F and Schmidt M A 2001 A combustion-based MEMS thermoelectric power generator Proc. Transducers '01 30-3

[7] Arana L R, Scheavitz S B, Franz A J, Schmidt M A and Jensen K F 2003 A microfabricated suspended-tube chemical reactor for thermally efficient fuel processing J. Microelectromech. Syst. 12 600-12

[8] Yoshida K, Tanaka S, Hiraki H, and Esashi M, $2006 \mathrm{~J}$. Micromech. Microeng. 16 S191-S197

[9] Miyamoto N, Terazaki T, Fujita T, Nomura M, Saito K, Tanaka Y, Nakamura $\mathrm{O}$ and Yamamoto $\mathrm{T}, 2006$ Development of a Thermally Efficient Microreactor with a Methanol Reformer for Small PEMFC Systems, Fuel Cell Seminar 2006 